\title{
New in 2005
}

This issue marks the turning point for Skull Base: An Interdisciplinary Approach. After 14 years of effort, we are now listed in Medline. It is absolutely wonderful news for us all: contributors, readers, and publisher alike. I am sure that our readership and skull base societies will join me in congratulating Thieme on this achievement.

The journal itself is going to change this year. The editorial board is being re-structured radically to reflect and represent the readership more accurately and effectively. A European office has now opened in London to receive your submissions, and your papers will be published electronically within one month of their acceptance (see the eFirst Editorial in this issue). So the publication process will be accelerated dramatically and the infuriating delays that beset authors in the past will be eradicated. Our contributors will be able to get their message to our readership faster than any other journal-an attractive proposition.

We wish to encourage more active participation from all our readers, wherever they may be, and will be supporting your national and continental societies in a much more visible and practical way. In return, we invite you to correspond with us on issues arising from articles published in the journal or on important topics that affect your clinical practice or training. The recent excellent meeting of the International Skull Base Society in Sydney demonstrated that Skull Base Surgery is developing in every continent along interdisciplinary lines. What affects the surgeons on one continent this year will surely affect others elsewhere next year and we want to hear about it now.

New sections are scheduled to appear throughout this year, for example: "How We Do It," "structured subject reviews," issues that focus on particular subjects, etc. The topics will be farreaching and will cover subjects that have been ignored previously, such as training, counseling, management of complications, practice issues, as well as surgical approaches and techniques. We will invite the leaders in our field to contribute these but would also welcome your views and manuscripts. Our Instructions to Authors also will be changing. Abstracts must be structured to make the papers more readable and attractive to the "search engine browser" that most of us have become in this electronic age. With your support we can take our journal forward, increase its citational index, and make it the first choice for prospective authors.

Michael Gleeson, M.D. Co-Editor in Chief ${ }^{1}$

Skull Base, volume 15, number 1, 2005. Address for correspondence and reprint requests: Michael Gleeson, M.D., Department of Otolaryngology and Skull Base Surgery, Guy's Hospital, London SE1 9RT, UK. E-mail: michael.gleeson@kcl.ac.uk. ${ }^{1}$ Department of Otolaryngology and Skull Base Surgery, Guy's Hospital, London, United Kingdom. Copyright (C) 2005 by Thieme Medical Publishers, Inc., 333 Seventh Avenue, New York, NY 10001, USA. Tel: +1(212) 584-4662. 1531-5010,p;2005,15,01,001,001,ftx,en;sbs00424x. 